\title{
Modelling of Economic Growth in Russian Agriculture
}

Tolmachev M.N.

Plekhanov Russian University of Economics, Saratov Socio-Economic Institute

Yashin N.S.

Plekhanov Russian University of Economics, Saratov Socio-Economic Institute

Grigoryeva L.L.

Kazan Federal University, Institute of Language, 420008, Kazan, Russia

Doi:10.5901/mjss.2014.v5n24p458

\begin{abstract}
Abstarct
The article deals with the experience and problems of production funds building in Russian agriculture. Factors of agricultural production best reflecting dynamics of output in agriculture are substantiated. The model of agricultural production in $1996-$ 2012 was built.
\end{abstract}

Keywords: production function, agricultural production, factors of agricultural production, econometric modelling

An important part of economic growth in agriculture is the production function connecting output with labor cost, volume of basic funds and other factors of production.

Apparatus of production functions is sufficiently well constructed for the developed market economies; many foreign and national literary works are devoted to it. At the same time, under conditions of Russian economy, essential problems of production funds building arise. The basic difficulties appear with evaluation of production factors cost of the basic funds and labor. Under conditions of intensive structural shifts, indices of traditional production factors can not reliably reflect information necessary for the production function building. For example, in 1996-2012 in agricultural organizations the number of workers decreased practically by a fourth, the cost of basic funds in comparable prices - by $21 \%$, production of goods increased by $33 \%$. Thus, the question arises - whether it is appropriate in Russian economy to use the production factors and functional form which the simple production function is.

The Gross Value Added (GVA) or agricultural production can be viewed as indices reflecting the output change in agriculture. The choice of output index depends on research goals, specification of production functions and moreover the availability of statistical data. The use of different indices as the output measure constrains production function and interpretation of the results obtained.

In picture 1 indices of GVA's physical volume and agricultural production are presented. As it can be seen, directions of indices change considered as output indices are equal although differ quantitatively. Physical volume of agricultural production had increased from 1995 to 2012 by $26,2 \%$, while GVA - by $51.6 \%$. The difference is explained by volume of interim consumption and correlation of output prices and interim consumption. 


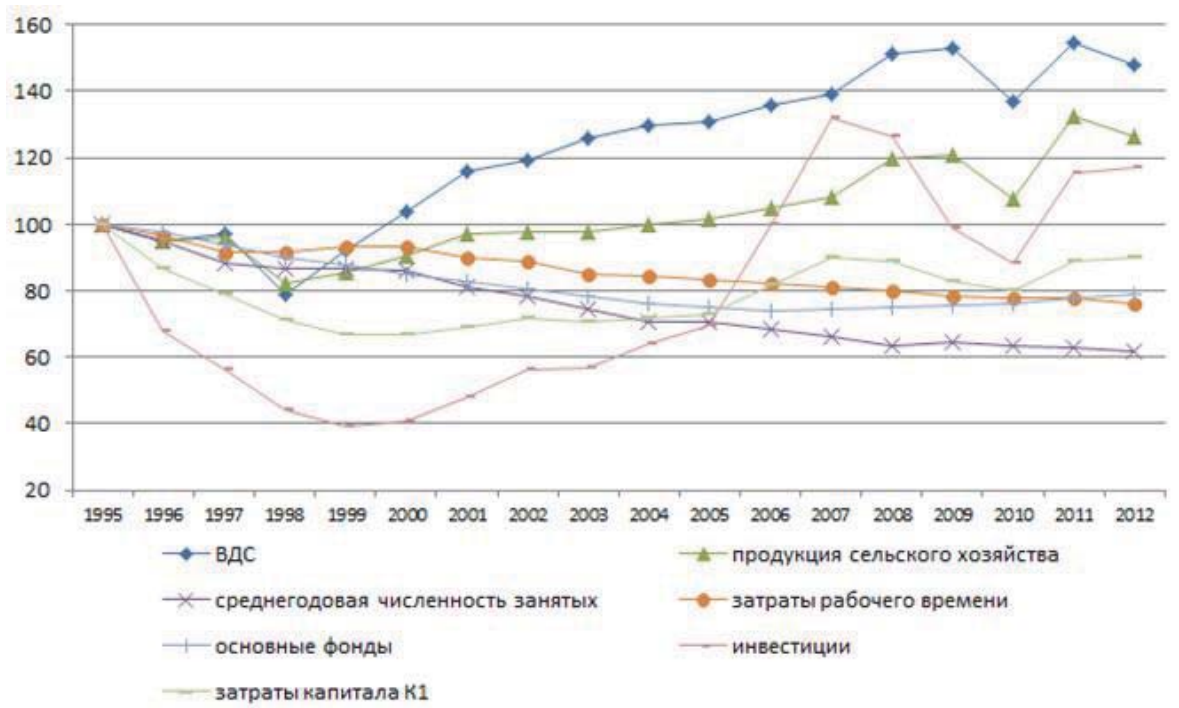

Picture 1. Dynamics of output and production factors in Russian agriculture in 1996-2012 (in percents by year 1995)

The number of the employed and hours performed are as a rule regarded as evaluation of labor costs. In the first case it is supposed that labor costs are proportional to reserves of labor resources. In Russian statistics average annual number of the employed in agriculture is calculated. People who have worked in agricultural organizations and organizations serving agriculture in peasant farm economy and those occupied by individual labor activity without formation of legal entity and employed in agricultural production for sale belong to them [2, 22 p.].

The more precise index reflecting labor costs is the combined labor time input. On the basis of the selective research on the employment, Russian statistics calculates general amount of the hours performed at all types of works on the production of goods and services. This index characterizes a number of actually performed man-hours at all types of works on the production of goods and services (for primary and secondary employment and also agricultural, forest, hunting and fishing products in domestic economies for sale as well as for self-use on the territory of the country. It is calculated by multiplication of labor places for each kind of works over average actual working time for every working place $[2,22$ p.].

Russian agriculture starting from 1999 is characterized by weak connection between the dynamics of output and labor costs in agriculture (pict.1) While the indices of output increased, the labor costs demonstrated the opposite tendency, the number of the employed in agriculture decreasing at a faster pace than the quantity of the hours performed that indicates the increase in the intensity of labor force business.

Evaluation of capital costs is the most complicated during the production function building. During its evaluation a number of questions arise on the methods of costs and estimation of their quality changes.

Evaluation of basic funds must be presented as an aggregated index taking into account quality changes in separate production units connected with their aging and wear and change in technological level. To build such estimation information on input funds, their productivity in comparison with those already existing, terms of the equipment's service, the cost of the equipment's repair is needed [3, 120-121].

Russian Statistics calculates the index of the basic funds' volume, dynamics of which in agriculture is presented in picture 1. As in case with labor cost, dynamics of the basic funds' physical volume of GVA does not reveal visible similarity with dynamics of GVA volume and agricultural production. The increase of output indices is accompanied by decrease in the index of the the basic funds' physical volume.

Besides, the index of the basic funds' physical volume does not consider the change in volumes of basic funds' agricultural assignment in sector «Domestic farms», despite the fact that in population's farms a remarkable part of agricultural products is produced $-43.2 \%$ in 2012. Production of agricultural goods in population's farms is hand-made, at the same time capital input is taken into account in index of the basic funds' physical volume, since in a village some operations (ploughing) are completed by the agricultural organizations' machinery.

From the point of view of the production function building among the considered production factors, in Russian economy factor which could influence the output dynamics is not evidently taken into account. From the formal point of view, it should be such a factor that its base index would have decreased more during decline than indices of GVA's 
physical volume or agricultural production. And during rise this factor must demonstrate outstripping increase. From economic point of view, it should be such a factor that would influence significantly the dynamics of output. Many researchers view investments as such a factor. Investments demonstrate much greater decrease than output, they are important for economic growth and are scarce in Russian agriculture. Dynamics of the investments' physical volume in main capital in agriculture is shown in picture 1.

In our opinion, taking into account investments as a factor of capital input would be not correct enough, since contribution of already existing basic funds would not be considered.

Whereas, with the change towards market conditions many basic funds depreciated, old funds were not fully used. This reflects decrease in their importance as a factor of production. Besides, effectiveness of newly added basic funds is higher than the old ones. This raises methodological problem of incommensurability of the new and old basic funds during basic indices construction of the basic funds' physical volume. In such a situation it is not correct to sum up the input evaluation of the old and new funds.

The simpiest way to obtain capital input estimation in which old funds input is reduced and input of the funds being introduced is increased is the aggregate's construction [4, 143p].

$$
K_{1}=K^{\beta} I^{1-\beta} \text {, }
$$

where $\mathrm{K}$ and $\mathrm{I}$ - indices of basic funds and investments physical volume;

$\beta$-constant, accepts values from 0 to 1 .

According to calculations made by V.A. Bessonov [3,144p], value $\beta=2 / 3$ well fit Russian economy. In picture 1 dynamics of capital input estimation $K_{1}$ obtained on the base (1) where ${ }^{\beta=2} / 3$ is presented. Dynamics of the given index best repeats changes of output indices in comparison with the indices of basic funds and investments' physical volume.

Picture 1 evidently demostrates that the diagrams of output indices (GVA and agricultural production) are situated higher than the diagrams of production factors indices in agriculture. This means that neither GVA nor agricultural production can be viewed as average between labor and capital input, since the result of averaging must be situated between values being averaged. Such combined dynamics of the given time rows can be described only by production function possessing level of homogeneity more than 1 or production function taken into account apart from the considered production factors, other factors resulting in outstripping increase of output in comparison with other factors of production.

Situation when input rise exceeds increase of the production factors indicates that in surroundings of t economic development occurs rather efficiently in terms of production factors use (if the factors were chosen rationally from the meaningful point of view and measured precisely enough). Such a situation is frequently interpreted in terms of high return on scale and positive technical progress.

Opposite situation when the dynamics of output is lower than the dynamics of production factors means that in surroundings of period t factors are used uneffectively. In this case situation is frequently explained in terms of low return on scale or negative technical progress. Both situations mean that in surroundings of period $t$ linear-homogeneous production function cannot be used [1,28p.].

Thus, economic rise cannot be explained with the help of production factors such as labor and capital. Nonetheless, it can be explained by these factors' productivity rise that reflects investment in output of all other factors not taken into account directly as arguments of production function. This residual is called combined factor productivity or Solow residual named after Robert Solow - an economist who was the first one to suggest such a method in the fifties of the last century [5]. Solow considers such an approach as a measure of technical progress.

$Y=A \cdot F(K, L)$

where $Y$ - indices of physical volume of production output;

A -combined factor productivity;

$L$-indices of labor costs.

We evaluated different types of production functions with different factors of labor and capital costs. As a result modified production function Cobb-Douglas taking into account technical progress was chosen:

$Y=a e^{p t} K^{b} L^{1-b} e^{u},(2)$

where $\mathrm{t}$ - time factor;

$p$-permanent pace of technical progress;

$u$-accidental mistake

Initial data for estimation of production function (2) are presented as basic indices (year $1995-100 \%)$. Index of physical volume of agriculture for all types of farms is presented as output index; index of the combined working time 
input as evaluation of labor cost and temporal rows of three indices were used as evaluation of capital input: in model 1 index of physical volume of basic funds, in model 2 - index of investments' physical volume, in model 3 - average geometric weighted of physical volume indices of basic funds and investments calculated according to (1), where $\beta=2 / 3$. Production function (2) results in linear form

$$
\ln \frac{Y}{L}=\ln a+p t+b \ln \frac{K}{L}+u
$$

And can be estimated by the method of the smallest squares. Results of the production function's parameters evaluation on the basis of annual data for the period 1996-2012 are presented in the table.

Table. Estimation of production factors function $\ln ^{\ln \frac{Y}{L}=\ln a+p t+b \ln \frac{K}{L}}$ in agriculture in Russia in 1996-2012

\begin{tabular}{|c|c|c|c|c|c|}
\hline Model & $\ln a$ & $p$ & $b$ & Coefficient of determination & Darbin-Watson statistic \\
\hline Model 1 & $\begin{array}{c}-0,118 \\
(0,004)\end{array}$ & $\begin{array}{c}0,038 \\
(0,000)\end{array}$ & $\begin{array}{c}0,643 \\
(0,055)\end{array}$ & 0,924 & 1,916 \\
\hline Model 2 & $\begin{array}{c}0,004 \\
(0,946)\end{array}$ & $\begin{array}{c}0,024 \\
(0,000)\end{array}$ & $\begin{array}{c}0,176 \\
(0,005)\end{array}$ & 0,950 & 2,081 \\
\hline Model 3 & $\begin{array}{c}0,013 \\
(0,795)\end{array}$ & $\begin{array}{c}0,025 \\
(0,000)\end{array}$ & $\begin{array}{c}0,496 \\
(0,001)\end{array}$ & 0,954 & 2,152 \\
\hline
\end{tabular}

In brackets levels of parameters' values significance are presented.

In model 1 value of output elasticity coefficient for the capital b slightly exceeds $5 \%$ level. This model is quite usable for estimation of agricultural production. However, the value of regression coefficient when $b$ significantly exceeds international recommendations for evaluation of the capital output elasticity.

The use of investments capital costs in model 2 gives significant equality of regression. In this case increase in physical volume of investments by $1 \%$ increases physical volume of agricultural production by $0.176 \%$ and 1 percent rise of the combined working time input - by $0.824 \%$.

The use of the combined estimation of basic funds and investments in model 3 as capital input provides output elasticity value on capital which equals 0.496 . This value is significantly higher than the one used by the experts for the developed economies (0.3), however not significantly different from the capital output elasticity in the developing economies (0.4). In connection to this fact model 3 is more preferable than model 1 . For model 3 production function (2) will be as follow:

$$
Y=1,013 e^{0,025 t} K^{0,496} L^{0,504} \text {. (3) }
$$

In general it was noticed that more closely different estimations of factors of production repeat dynamics of output during single estimation of another factor, the smaller the coefficient of elasticity of this factor is.

We should note that indices of average annual number of the employed in agriculture were used as labor costs. In this case estimation of coefficient $b$ practically did not differ from the corresponding estimations in models 2 and 3. Because of the above named lack of number of the employed, estimations of production function parameters are not given.

Thus, the use of the average geometric weighted of basic funds and investments indices' physical volume with weights $2 / 3$ and $1 / 3$ accordingly as capital cost and index of combined labor time as labor cost best reflect dynamics of agricultural production.

In picture 1 indices of agricultural production actually and theoretically calculated by (3) are presented. 


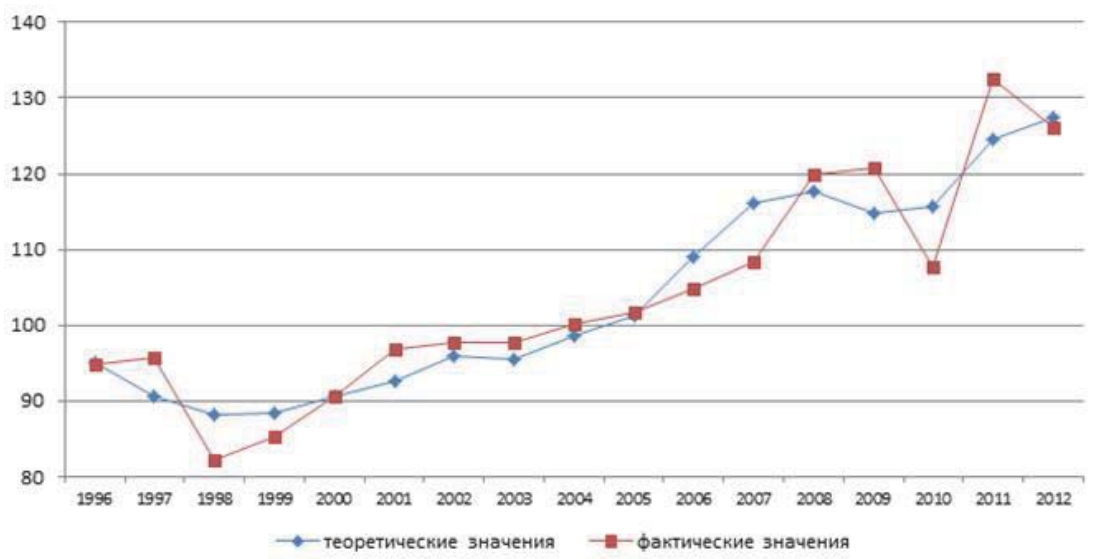

Picture 1. Actual and theoretical indices of agricultural production (in percents in 1995)

The conducted analysis shows that starting from 1999 intensive increase in agricultural production was observed, pace of which significantly outpaced paces of production factors costs. The observed increase occured after the significant decrease in agricultural production in the beginning - middle of the 90-s of the last century. Agricultural production in the comparable prices decreased in 1995 by a third, in 1998 - by $45 \%$ in comparison with 1990 . At the same time production factors in 1995 remained on the level of 1990, in 1998 decreased by 10\% that indicates sharp decrease in the combined factor productivity in agriculture with the beginning of market reforms. Evidently, the starting rise of productivity under conditions of the restricted number of production factors which in a higher degree can be explained by a significant rise of the effectiveness of the production factors use.

The continued rise of the combined factor productivity is necessary to take into account during forecasting of agricultural production, since prognostic estimations based only on the dynamics of production factors in such a situation will significantly be shifted down.

\section{Bibliography}

Bessonov V.A., Tsuhlo S.V. Analysis of Russian economic transitional dynamics. - M.: IETP, 2002. -186p.

Agriculture, hunting and foresting in Russia. 2009: Journal - M.: Russian Statistics, 2013. - 462p.

Factors of economic growth in RF regions. - M.: IETP, 2005. - 278p.

Factors of economic growth of Russian economy. M.: IETP, 2003. - 389p.

Solow R.M. Technical Change and the Aggregate Production Function // The Review of Economics and Statistics. 1957. Vol. 39. No. 3. P. 312-320.

Information about the authors

Tolmachev Mikhail Nikolaevich, PHD in economic sciences, assistant professor, head of the department of statistics in Saratov socioeconomic institute (affilliate) of Plekhanov Russian economic university, tel.: (8452) 211-767; Email: tolmachev-mike@yandex.ru

Yashin Nikolay Sergeevich, , PHD in economic sciences, professor, director's deputy on academic work and innovations in Saratov Для таблиц socio-economic institute (affiliate) of Plekhanov Russian economic university, tel.: (8452) 333-251; Email: yashin@ssea.runnet.ru

ВДC - GVA

Среднегодовая численность занятых - Average annual number of the employed

Основные фонды - Basic funds

Затраты капитала k1 - Capital input k1

Продукция сх - Agricultural production

Затраты рабочего времени - Working time costs

Инвестиции - Investments

Теоретические значения - Theoretical values

Фактические значения - Actual values 